\title{
Testing the association between blood type and COVID-19 infection, intubation, and death
}

\section{Authors}

- Michael Zietz

0000-0003-0539-630X

Department of Biomedical Informatics, Columbia University Irving Medical Center

- Jason Zucker

0000-0001-6987-6412

Department of Medicine, Columbia University Irving Medical Center

- $\quad$ Nicholas P. Tatonetti

0000-0002-2700-2597

Department of Biomedical Informatics, Columbia University Irving Medical Center; Department of Systems Biology, Columbia University Irving Medical Center; Department of Medicine, Columbia University Irving Medical Center; Institute for Genomic Medicine, Columbia University Irving Medical Center

$\dagger$ —C Corresponding author: nick.tatonetti@columbia.edu (Nicholas P. Tatonetti) 


\section{Abstract}

The rapid global spread of the novel coronavirus SARS-CoV-2 has strained healthcare and testing resources, making the identification and prioritization of individuals most at-risk a critical challenge. Recent evidence suggests blood type may affect risk of severe COVID-19. We used observational healthcare data on 14,112 individuals tested for SARS-CoV-2 with known blood type in the New York Presbyterian (NYP) hospital system to assess the association between $\mathrm{ABO}$ and $\mathrm{Rh}$ blood types and infection, intubation, and death. We found slightly increased infection prevalence among non-O types. Risk of intubation was decreased among A and increased among $\mathrm{AB}$ and $\mathrm{B}$ types, compared with type $\mathrm{O}$, while risk of death was increased for type $\mathrm{AB}$ and decreased for types $\mathrm{A}$ and $\mathrm{B}$. We estimated Rh-negative blood type to have a protective effect for all three outcomes. Our results add to the growing body of evidence suggesting blood type may play a role in COVID-19.

\section{Background}

The novel Coronavirus disease (COVID-19, caused by the SARS-CoV-2 virus) has spread rapidly across the globe and has caused over 21.1 million confirmed infections and over 761,000 deaths worldwide as of August 17, 2020 [1]. A number of risk factors for COVID-19 morbidity and mortality are known, including age, sex, smoking, hypertension, diabetes, and chronic cardiovascular and respiratory diseases [2,3].

Recent work has demonstrated an association between ABO blood types and COVID-19 risk. Using data from Wuhan and Shenzhen, Zhao et al. found a greater proportion of A and a lower 
proportion of O blood types among COVID-19 patients, relative to the general populations of Wuhan and Shenzhen [4]. Similarly, using a meta-analysis of data from Italy and Spain, Ellinghaus et al. [5] found a higher risk of COVID-19 among A and a lower risk among O blood types. Conversely, however, they estimated lower odds of mechanical ventilation for all non-O types, though the estimated odds ratios were not statistically significant at the $5 \%$ level for this outcome.

The ABO blood type trait reflects polymorphisms within the $A B O$ gene. This gene is associated with a number of other traits, including risk factors for COVID-19 morbidity and mortality. For example, genome-wide association studies have associated variants within $A B O$ to activity of the angiotensin converting enzyme (ACE) [6], red blood cell count, hemoglobin concentration, hematocrit, $[7,8,9,10]$, von Willebrand factor $[11,12,13,14]$, myocardial infarction $[15,16]$, coronary artery disease [16,17,18,19,20], ischemic stroke [12,18,21], type 2 diabetes [22,23,24], and venous thromboembolism [25,26,27,28,29,30,31,32]. A 2012 meta-analysis found that, in addition to individual variants, a non-O blood type is among the most important genetic risk factors for venous thromboembolism [33]. These conditions are also relevant for COVID-19. For example, coagulopathy is a common issue for COVID-19 patients [34,35,36,37,38,39,40], and risk of venous thromboembolism must be carefully managed [41].

The numerous associations between conditions and both blood type and COVID-19 provide reason to believe true associations may exist between blood type and morbidity and mortality due to COVID-19. In addition, previous work has identified associations between ABO blood groups and a number of different infections or disease severity following infections, including 
SARS-CoV-1 [42], P. falciparum [43], H. pylori [44], Norwalk virus [45], hepatitis B virus [46], and N. gonorrhoeae [47].

$\mathrm{Rh}(\mathrm{D})$ phenotypes (positive and negative $\mathrm{Rh}$ blood types) are associated with very few diseases compared to $\mathrm{ABO}$ [48]. Like $\mathrm{ABO}, \mathrm{Rh}$ type is important for type compatibility and immune response. For example, hemolytic disease of the newborn is a concern when $\mathrm{Rh}(\mathrm{D})$ is mismatched between mother and offspring [49]. Other studies have found evidence that $\mathrm{Rh}$-positive individuals are protected against the effects of latent toxoplasmosis [50], though Toxoplasma gondii is a eukaryotic parasite [51], not a virus like SARS-CoV-2.

Within the United States, New York suffered among the worst outbreaks during the early phases of the pandemic. As of August 22, New York City has recorded 228,144 confirmed infections and 19,014 deaths [52]. We sought to understand the association between SARS-CoV-2 infection/COVID-19 and blood type using electronic health record (EHR) data from New York-Presbyterian/Columbia University Irving Medical Center (NYP/CUIMC) hospital in New York City, USA. We compared both $\mathrm{ABO}$ and $\mathrm{Rh}(\mathrm{D})$ blood types, and we investigated initial infection status and two severe COVID-19 outcomes: intubation and death. We evaluated potential confounding due to population stratification using a multivariate analysis, and we report clinically meaningful measures of effect.

\section{Results}

We determined blood types using laboratory measurements recorded in the NYP/CUIMC EHR system. After removing likely errors, such as individuals with contradictory blood type results, we identified 14,112 adult individuals with known blood types who received at least one 
SARS-CoV-2 swab test (Table 1, Supplementary Figure S1). We performed chi-squared tests of independence and found insufficient evidence to conclude that the blood group frequencies differ between SARS-CoV-2-tested and non-tested groups (Supplementary Table 1). Individuals were considered initially SARS-CoV-2 positive $(\mathrm{COV}+)$ if they tested positive on their first recorded test or within the following 96 hours. We evaluated associations between blood types and outcomes using three comparisons: infection prevalence among initial tests and survival analysis for intubation and death among individuals with infections confirmed by swab test. We report on clinical data as of August 1, 2020.

The unadjusted prevalence of initial infection was higher among A and B blood types and lower among $\mathrm{AB}$ types, compared with type $\mathrm{O}$ (Table 2, Figure 1). To avoid bias with respect to healthcare utilization, length of hospital stay, and potential in-patient infection, we evaluated the prevalence of infection among individuals only during the first encounters in which they were tested. In addition, to account for the considerable risk of false negative tests $[55,56]$ and the fact that providers would repeat the test in patients with high clinical suspicion for COVID-19 [57], any positive test during the first 96 hours of an encounter was considered evidence of initial infection.

Blood type frequencies vary across ancestry groups [53], so we evaluated the confounding effect of ancestry by adjusting for race/ethnicity (proxies for ancestry). We compared infection prevalence with linear regression, using reference groups $\mathrm{O}$ for $\mathrm{ABO}$ and $\mathrm{Rh}$-positive for $\mathrm{Rh}(\mathrm{D})$, and using bootstrap to compute $95 \%$ confidence intervals for each estimate [54]. With adjustment for patient race and ethnicity, prevalences among types $\mathrm{A}, \mathrm{AB}$, and $\mathrm{B}$ were higher 
than type $\mathrm{O}$. Rh(D) negative individuals had a $2.7 \%$ lower risk of initial infection after adjustment for ancestry, consistent with a lower risk before adjustment.

Next, we examined intubation and death using a survival framework to understand how blood type affects progression to disease outcomes over time. Specifically, we used the Fine-Gray model [58] to estimate cumulative incidence functions by blood type while accounting for competing risks and adjusting covariates. Death and recovery were competing events for intubation and recovery was a competing event for death. Cohort entry was defined as the time of a patient's first positive test result or the start of a hospital encounter if the first positive test occurred during the first 96 hours of the hospitalization. In accordance with CDC guidelines for returning to work $[59,60]$, we defined a patient as having recovered only when 10 days had passed since the patient entered the cohort and only once the patient had been discharged. Patients appearing on before July 30 were considered, and outcomes beyond August 1, 2020 were censored.

Blood type A was at decreased risk of both intubation and death relative to type $\mathrm{O}$, while type $\mathrm{AB}$ was at increased risk of both outcomes (Figure 1, Table 2). Conversely, we found that type B individuals were at higher risk of intubation but at lower risk of death, compared with type O. Individuals negative for $\mathrm{Rh}(\mathrm{D})$ were at decreased risk for both intubation and death, consistent with a lower risk of initial infection. Overall, we estimate between 0.1 and 8.2 percent absolute risk differences between blood groups, after adjusting for race and ethnicity. 


\section{Discussion}

Better understanding COVID-19 is imperative given the current pandemic's toll. We investigated whether blood type is relevant for risk of infection, intubation, and death. Overall, we found modest but consistent risk differences between blood types. After adjusting for ancestry (the relevant confounder for this analysis), estimated risk differences were larger for intubation and death outcomes than for initial infection. We estimate larger risk differences between Rh blood types than between $\mathrm{ABO}$ types, with Rh-negative individuals being at lower risk of all three outcomes. Type A had lower risk of intubation and death compared with types AB and O. Only type B had inconsistent effects between intubation and death-type B increased risk of intubation and decreased risk of death compared to type $\mathrm{O}$. We also found consistent evidence for protective associations between Rh negative blood groups and SARS-CoV-2 infection, intubation, death. Overall, blood type appears to have a consistent effect, though the magnitudes of these effects on risk of intubation or death are modest, and our estimates have large uncertainties relative to their magnitudes. The relatively large estimated errors in our analysis also suggest modest effect sizes and that greater sample sizes or meta-analyses are needed to estimate these effects more precisely.

After adjusting for ancestry by proxies of race and ethnicity, we found that types A and B conferred greater risk of an initial positive test compared to type $\mathrm{O}$, while type $\mathrm{AB}$ (the rarest), conferred a very small risk decrease $(0.2 \%)$. These results are consistent with an association discovered for SARS-CoV-1, in which O blood groups were less common among SARS patients [42]. Our results are also mostly consistent with the results reported by Zhao et al. [4], where 
non-O types appear to be at greater risk of infection, and with Ellinghaus et al. [5], where non-O appear to be at greater risk of infection but at lesser risk of mechanical ventilation, though the authors note that this decreased risk is not statistically significant at the $5 \%$ level. Unlike Ellinghaus et al., though, we estimate slightly higher risk for types $\mathrm{B}$ and $\mathrm{AB}$ relative to $\mathrm{O}$ for intubation.

Our results are based on data collected as part of hospital care during the early course of the pandemic, where outpatient testing was severely limited due to testing capacity and supply limitations. As such, our data are highly enriched for severely-ill patients, and the absolute risk values we report are not generalizable to all SARS-CoV-2-infected individuals. A considerable fraction of infections are mild or asymptomatic [61,62,63,64], while our data represent predominantly the most severe cases. Selection bias is a fundamental limitation of our study, so all our effect estimates are conditional on presentation to the hospital. Nonetheless, we minimized additional selection bias by making cohort criteria for cases and controls differ only with respect to the outcome of interest. Moreover, we found concordance between SARS-CoV-2-tested individuals and the general population at NYP/CUIMC in terms of blood type (Supplementary table 1). Consequently, our results are not affected by selection bias with respect to blood type, unlike some other blood type case/control study designs — particularly those using blood donors as controls, where enrichment of type O can be expected [5].

False negatives and time delay between test administrations and the return of their results both introduce noise to this analysis. We attempted to account for these biases by setting cohort entry at the time of first contact with the hospital when the patient tested positive less than 96 hours thereafter. This definition is imperfect, as 96 hours is sufficient for an individual infected shortly 
after admission to test positive (albeit with probability roughly 0.33 ) [65], but it is necessary to allow sufficient adjustment for the considerable time delay and retesting following false negatives. Another source of noise is the fact that not all intubations and deaths following a confirmed infection are related to COVID-19 (e.g. intubation during unrelated surgery). We defined recovery in an attempt to minimize this issue, though we recognize our definition is imperfect. Patients may be discharged prematurely and later return following onset of severe symptoms. Moreover, our 10 day cutoff for recovery is based on CDC guidelines for returning to work $[59,60]$, which may be refined as additional evidence becomes available. Further work is needed to refine the definition of recovery and to determine which outcomes may be causally linked to COVID-19.

The $A B O$ gene is highly polymorphic [66], and blood types have considerably different distributions across ancestry groups [53]. Like ABO, Rh groups are not distributed equally across race/ethnicity groups, with enrichment of Rh-negative among white and non-Hispanic individuals (Table 1). In addition, negative Rh blood groups are less common, representing only $9 \%$ of individuals in our data. While genetic data were not available for the patients included in our study, we used self-reported race and ethnicity as imperfect proxies for genetic ancestry. Adjusting for these covariates had a noticeable effect on our comparison of infection prevalence, but did not have an equally relevant effect on intubation or death (Figure 1, Table 2). This suggests that blood type may have a lesser, more confounded effect on infection prevalence than on intubation or death following confirmed infection. Nonetheless, race and ethnicity cannot fully capture ancestry, so the associations between blood types and COVID-19 we report may still be confounded by ancestry, even after adjustment. Further work is needed to better 
understand any potential residual confounding due to ancestry, not captured by race and ethnicity.

\section{Conclusion}

In this study we found evidence for associations between $\mathrm{ABO}$ and $\mathrm{Rh}$ blood groups and COVID-19. Using data from NYP/CUIMC, we found moderately increased infection prevalence among non-O blood types and among Rh-positive individuals. Intubation risk was increased among $\mathrm{AB}$ and $\mathrm{B}$ types, and decreased among $\mathrm{A}$ and Rh-negative types. Risk of death was slightly increased among type $\mathrm{AB}$ individuals and was decreased among types $\mathrm{A}, \mathrm{B}$, and Rh-negative types. All estimates were adjusted for patient ancestry using self-reported race and ethnicity. Our results add further evidence to the previously discovered associations between blood types and COVID-19.

\section{Acknowledgements}

We would like to thank Ben May and Vijendra Ramlall for assistance with data collection and periodic updates to the patient data. We would also like to thank Nicholas Giangreco, Undina Gisladottir, and Dr. Phyllis Thangaraj for helpful discussions regarding risk factor definitions. MZ is funded by NIH T15 LM007079, and NPT is funded by R35GM131905. 


\section{Author contributions}

MZ and NPT conceived and designed the study. MZ carried out the statistical analysis with advice from NPT. JZ and MZ created the cohort entry and exit criteria. MZ and NPT wrote, revised, and approved the final version of the manuscript.

\section{Competing interests}

The authors have no competing interests to disclose.

\section{Methods}

We identified the cohort for this study by filtering the NYP/CUIMC data warehouse for patients with a recorded SARS-CoV-2 test and those having a recorded blood type. Next, we removed any individual with multiple, contradictory blood type measurements, reflecting likely errors in the data. Finally, we excluded individuals below age 18 from our analysis.

Blood group was determined using laboratory measurements coded using descendant concepts of LOINC LP36683-8 (ABO and Rh group). Individuals with contradictory measurements were excluded. Intubation was assessed using completed procedures having the procedure description, "Intubation." We grouped race into five categories and ethnicity into two. Specifically, we considered only Asian, Black/African-American, and White, categorizing other listed races (all of which were small minorities) as 'Other', and missing or declined race as 'Missing'. Ethnicity was grouped as either Hispanic or non-Hispanic. 
medRxiv preprint doi: https://doi.org/10.1101/2020.04.08.20058073; this version posted September 10, 2020. The copyright holder for this

We sought to estimate total effects of blood type on COVID-19 outcomes. Using a graphical model (Supplementary Figure S2), we identified ancestry as the only confounding variable for an estimate of total effect, since blood type is genetic and varies across ancestry groups. As genetic data were not available, we used self-reported race and ethnicity as proxies for ancestry. We were unable to identify a method to alleviate selection bias in our data, so the effects we report are conditional on presence at NYP/CUIMC.

We considered three outcomes: initial infection, intubation, and death. Our evaluation of initial infection sought to assess the infection prevalence differences among individuals presenting to the hospital, not those potentially infected at the hospital or long after their first test. Due to the high risk for false negatives [55,56], we considered any positive test less than 96 hours after the start of an encounter as evidence of initial infection. Initial infection risk differences between blood types were assessed using linear regression, and race/ethnicity were adjusted by including them as covariates. We used Austin's bootstrap method to compute 95\% confidence intervals for all risk estimates [54], using 1000 bootstrap iterations.

We assessed intubation and death as severe outcomes of COVID-19, and evaluated blood type effects using survival analysis. Individuals entered the at-risk cohort either at the time of their first positive test result, or at the time of first contact with the hospital when the first positive test occurred within 96 hours of the start of a hospital encounter. Patients with Do-Not-Intubate orders were excluded from consideration for the intubation outcome. We defined a patient as recovered only after being discharged from the hospital and only once 10 days have passed since cohort entry. Death and recovery are competing risks for intubation, and recovery is a competing risk for death. Finally, outcomes beyond August 1 were censored, as this was the last date for 
which we have data available. Intubation and death were assessed using Fine-Gray models, which can estimate cumulative incidences. As before, race and ethnicity were adjusted by including them as covariates, and confidence intervals were computed with 1000 bootstrap iterations.

This study is approved by the IRB (\#AAAL0601). We conducted our analyses using the R language, using the cmprsk package [67] implementation of the Fine-Gray model. The manuscript was written openly on GitHub using Manubot [68].

\section{Data availability}

While our data from NYP/CUIMC are protected by HIPAA and cannot be released, we have made all code used for our analysis available at https://github.com/zietzm/abo_covid_analysis.

\section{Code availability}

We have made all code used for our analysis available at https://github.com/zietzm/abo_covid_analysis. 
medRxiv preprint doi: https://doi.org/10.1101/2020.04.08.20058073; this version posted September 10, 2020. The copyright holder for this preprint (which was not certified by peer review) is the author/funder, who has granted medRxiv a license to display the preprint in perpetuity.

It is made available under a CC-BY 4.0 International license .

\section{Tables}

Table 1: Summary demographics for SARS-CoV-2-tested individuals at NYP/CUIMC, stratified by blood type. $N$ is the number of individuals having the given blood type who had at least one recorded test for SARS-CoV-2. Age is reported as the median and interquartile range (25-75). Percents are reported relative to individuals having the blood type, except the $N$ row, where percents are by blood group type ( $A B O$ or $R h)$ and are relative to all individuals in the study.

\begin{tabular}{|c|c|c|c|c|c|c|}
\hline & $\mathbf{A}$ & $\mathbf{A B}$ & $\mathbf{B}$ & $\mathbf{O}$ & Rh-neg & Rh-pos \\
\hline $\mathrm{N}$ & $4298(32.9)$ & $559(4.3)$ & $2033(15.6)$ & $6161(47.2)$ & $1195(9.2)$ & $11856(90.8)$ \\
\hline Age (IQR) & $58(37$ to 72$)$ & $57(37$ to 71$)$ & 57 (37 to 72$)$ & $55(36$ to 71$)$ & $56(37$ to 70$)$ & $56(37$ to 71$)$ \\
\hline Male (\%) & $1676(39.0)$ & $231(41.3)$ & $778(38.3)$ & $2339(38.0)$ & $430(36.0)$ & $4594(38.7)$ \\
\hline Hispanic (\%) & $1572(36.6)$ & $173(30.9)$ & $666(32.8)$ & $2583(41.9)$ & 389 (32.6) & $4605(38.8)$ \\
\hline \multicolumn{7}{|l|}{ Race } \\
\hline Asian (\%) & $71(1.7)$ & $21(3.8)$ & $89(4.4)$ & $123(2.0)$ & $16(1.3)$ & $288(2.4)$ \\
\hline Black (\%) & $629(14.6)$ & $95(17.0)$ & $493(24.2)$ & $1179(19.1)$ & $151(12.6)$ & $2245(18.9)$ \\
\hline Missing $(\%$ & $728(16.9)$ & $79(14.1)$ & $370(18.2)$ & $1093(17.7)$ & $192(16.1)$ & $2078(17.5)$ \\
\hline Other $(\%)$ & $1085(25.2)$ & $132(23.6)$ & $464(22.8)$ & $1715(27.8)$ & $263(22.0)$ & $3133(26.4)$ \\
\hline White $(\%)$ & $1785(41.5)$ & $232(41.5)$ & $617(30.3)$ & $2051(33.3)$ & $573(47.9)$ & $4112(34.7)$ \\
\hline \multicolumn{7}{|l|}{ Outcomes } \\
\hline Initially COV+ $(\%)$ & 754 (17.5) & $88(15.7)$ & $363(17.9)$ & $1060(17.2)$ & $164(13.7)$ & $2101(17.7)$ \\
\hline $\mathrm{COV}+(\%)$ & $786(18.3)$ & $94(16.8)$ & $392(19.3)$ & $1122(18.2)$ & $175(14.6)$ & $2219(18.7)$ \\
\hline $\mathrm{COV}+/$ Intubated (\%) & $111(2.6)$ & $17(3.0)$ & $78(3.8)$ & $193(3.1)$ & $24(2.0)$ & $375(3.2)$ \\
\hline COV+/Died (\%) & $104(2.4)$ & $15(2.7)$ & $46(2.3)$ & $166(2.7)$ & $11(0.9)$ & $320(2.7)$ \\
\hline
\end{tabular}


medRxiv preprint doi: https://doi.org/10.1101/2020.04.08.20058073; this version posted September 10, 2020. The copyright holder for this preprint (which was not certified by peer review) is the author/funder, who has granted medRxiv a license to display the preprint in perpetuity.

It is made available under a CC-BY 4.0 International license .

Table 2: Effect size estimates for blood types with and without correction for race and ethnicity. Risks computed using linear regression (for prevalence) or the cumulative incidence from Fine-Gray models (for intubation and death). Risk differences and ratios computed relative to $O A B O$ blood type and positive Rh(D) type.

\begin{tabular}{|c|c|c|c|c|c|c|c|}
\hline & & & Unadjusted & & & e/ethnicity adju & usted \\
\hline Outcome & $\begin{array}{c}\text { Blood } \\
\text { type }\end{array}$ & Risk & $\begin{array}{c}\text { Risk } \\
\text { difference }\end{array}$ & Risk ratio & Risk & $\begin{array}{c}\text { Risk } \\
\text { difference }\end{array}$ & Risk ratio \\
\hline \multirow{6}{*}{ Prevalence } & A & $\begin{array}{l}17.5(16.3 \text { to } \\
18.8)\end{array}$ & $0.3(-1.2$ to 1.9$)$ & $\begin{array}{l}1.02(0.93 \text { to } \\
1.12)\end{array}$ & $\begin{array}{l}18.0(16.8 \text { to } \\
19.2)\end{array}$ & $1.3(-0.3$ to 3.0$)$ & $\begin{array}{l}1.08(0.98 \text { to } \\
1.19)\end{array}$ \\
\hline & AB & $\begin{array}{l}15.7(12.8 \text { to } \\
18.7)\end{array}$ & $\begin{array}{l}-1.5(-4.5 \text { to } \\
1.7)\end{array}$ & $\begin{array}{l}0.91(0.74 \text { to } \\
1.10)\end{array}$ & $\begin{array}{l}16.8(13.9 \text { to } \\
19.8)\end{array}$ & 0.1 (-2.8 to 3.2$)$ & $\begin{array}{l}1.01(0.83 \text { to } \\
1.20)\end{array}$ \\
\hline & B & $\begin{array}{l}17.9(16.1 \text { to } \\
19.5)\end{array}$ & $0.7(-1.4$ to 2.6$)$ & $\begin{array}{l}1.04(0.92 \text { to } \\
1.16)\end{array}$ & $\begin{array}{l}18.0(16.3 \text { to } \\
19.7)\end{array}$ & $1.3(-0.7$ to 3.3$)$ & $\begin{array}{l}1.08(0.96 \text { to } \\
1.20)\end{array}$ \\
\hline & $\mathrm{O}$ & $\begin{array}{l}17.2(16.2 \text { to } \\
18.1)\end{array}$ & E & E & $\begin{array}{l}16.7(15.7 \text { to } \\
17.6)\end{array}$ & - & E \\
\hline & Rh-pos & $\begin{array}{l}17.7(17.0 \text { to } \\
18.4)\end{array}$ & - & E & $\begin{array}{l}17.6(16.9 \text { to } \\
18.3)\end{array}$ & - & - \\
\hline & Rh-neg & $\begin{array}{l}13.7(11.8 \text { to } \\
15.5)\end{array}$ & $\begin{array}{l}-4.0(-6.1 \text { to } \\
-2.0)\end{array}$ & $\begin{array}{l}0.77(0.66 \text { to } \\
0.88)\end{array}$ & $\begin{array}{l}14.9(13.0 \text { to } \\
16.8)\end{array}$ & $\begin{array}{l}-2.7(-4.7 \text { to } \\
-0.8)\end{array}$ & $\begin{array}{l}0.85(0.73 \text { to } \\
0.96)\end{array}$ \\
\hline \multirow{6}{*}{ Intubation } & A & $\begin{array}{l}17.2(14.2 \text { to } \\
20.1)\end{array}$ & $\begin{array}{l}-3.2(-7.5 \text { to } \\
0.3)\end{array}$ & \begin{tabular}{|l}
0.84 (0.66 to \\
$1.02)$
\end{tabular} & $\begin{array}{l}17.3(14.3 \text { to } \\
20.4)\end{array}$ & $\begin{array}{l}-2.9(-7.2 \text { to } \\
0.6)\end{array}$ & $\begin{array}{l}0.85(0.68 \text { to } \\
1.03)\end{array}$ \\
\hline & $\mathrm{AB}$ & $\begin{array}{l}21.8(12.3 \text { to } \\
31.7)\end{array}$ & \begin{tabular}{|l}
$1.4(-8.5$ to \\
$11.6)$
\end{tabular} & $\begin{array}{l}1.07 \text { (0.59 to } \\
1.57)\end{array}$ & $\begin{array}{l}22.1(12.8 \text { to } \\
32.1)\end{array}$ & $\begin{array}{l}1.8(-8.3 \text { to } \\
12.2)\end{array}$ & $\begin{array}{l}1.09(0.60 \text { to } \\
1.59)\end{array}$ \\
\hline & $B$ & $\begin{array}{l}22.9(18.6 \text { to } \\
27.6)\end{array}$ & $2.5(-2.5$ to 7.6$)$ & $\begin{array}{l}1.12(0.89 \text { to } \\
1.40)\end{array}$ & $\begin{array}{l}22.8 \text { (18.6 to } \\
27.5)\end{array}$ & $2.5(-2.7$ to 7.5$)$ & $\begin{array}{l}1.12(0.88 \text { to } \\
1.40)\end{array}$ \\
\hline & $\mathrm{O}$ & $\begin{array}{l}20.4(17.8 \text { to } \\
23.4)\end{array}$ & - & E & $\begin{array}{l}20.3(17.7 \text { to } \\
23.3)\end{array}$ & - & E \\
\hline & Rh-pos & $\begin{array}{l}20.3(18.4 \text { to } \\
22.1)\end{array}$ & E & - & $\begin{array}{l}20.2(18.4 \text { to } \\
22.1)\end{array}$ & - & - \\
\hline & Rh-neg & $\begin{array}{l}14.6(9.7 \text { to } \\
20.7)\end{array}$ & \begin{tabular}{|l}
$-5.7(-11.0$ to \\
$0.5)$
\end{tabular} & $\begin{array}{l}0.72(0.47 \text { to } \\
1.02)\end{array}$ & \begin{tabular}{|l}
$15.0(9.9$ to \\
$21.0)$
\end{tabular} & $\begin{array}{l}-5.2(-10.7 \text { to } \\
1.0)\end{array}$ & $\begin{array}{l}0.74(0.48 \text { to } \\
1.05)\end{array}$ \\
\hline \multirow{6}{*}{ Death } & A & $\begin{array}{l}13.3(11.0 \text { to } \\
15.7)\end{array}$ & $\begin{array}{l}-1.6(-4.9 \text { to } \\
1.6)\end{array}$ & $\begin{array}{l}0.89(0.71 \text { to } \\
1.11)\end{array}$ & $\begin{array}{l}13.2(10.9 \text { to } \\
15.6)\end{array}$ & $\begin{array}{l}-1.6(-4.9 \text { to } \\
1.6)\end{array}$ & $\begin{array}{l}0.89(0.71 \text { to } \\
1.12)\end{array}$ \\
\hline & AB & $\begin{array}{l}16.1(8.5 \text { to } \\
23.8)\end{array}$ & $1.2(-6.6$ to 8.9$)$ & $\begin{array}{l}1.08(0.58 \text { to } \\
1.62)\end{array}$ & $\begin{array}{l}16.2(8.7 \text { to } \\
23.5)\end{array}$ & $1.4(-6.4$ to 8.9$)$ & $\begin{array}{l}1.10(0.59 \text { to } \\
1.64)\end{array}$ \\
\hline & B & $\begin{array}{l}11.8(8.6 \text { to } \\
15.0)\end{array}$ & $\begin{array}{l}-3.1(-7.0 \text { to } \\
0.6)\end{array}$ & \begin{tabular}{|l}
$0.79(0.56$ to \\
$1.05)$
\end{tabular} & $\begin{array}{l}12.2(9.0 \text { to } \\
15.5)\end{array}$ & $\begin{array}{l}-2.6(-6.6 \text { to } \\
1.3)\end{array}$ & $\begin{array}{l}0.83(0.58 \text { to } \\
1.09)\end{array}$ \\
\hline & $\mathrm{O}$ & $\begin{array}{l}14.9(12.9 \text { to } \\
17.1)\end{array}$ & E & E & $\begin{array}{l}14.8(12.7 \text { to } \\
16.9)\end{array}$ & - & - \\
\hline & Rh-pos & $\begin{array}{l}14.5(13.0 \text { to } \\
16.0)\end{array}$ & E & 上 & $\begin{array}{l}14.5(13.0 \text { to } \\
16.0)\end{array}$ & E & - \\
\hline & Rh-neg & $\begin{array}{l}6.3(3.0 \text { to } \\
10.1)\end{array}$ & $\begin{array}{l}-8.2(-11.7 \text { to } \\
-3.8)\end{array}$ & $\begin{array}{l}0.44(0.21 \text { to } \\
0.72)\end{array}$ & $\begin{array}{l}6.4(3.0 \text { to } \\
10.3)\end{array}$ & $\begin{array}{l}-8.2(-11.7 \text { to } \\
-3.7)\end{array}$ & $\begin{array}{l}0.44(0.21 \text { to } \\
0.74)\end{array}$ \\
\hline
\end{tabular}




\section{Figures}

Figure 1: Estimated risk differences for blood types during the period from March 10 to August 1, 2020. Values represent risk differences for each blood type relative to the reference groups: O for $A B O$ and positive for $R h(D)$. Prevalence risk differences were computed using linear regression, while intubation and death were computed using the Fine-Gray model [58]. Differences and 95\% confidence intervals (CI) computed using Austin's method, including bootstrap [54]. Adjusted models include race and ethnicity as covariates.

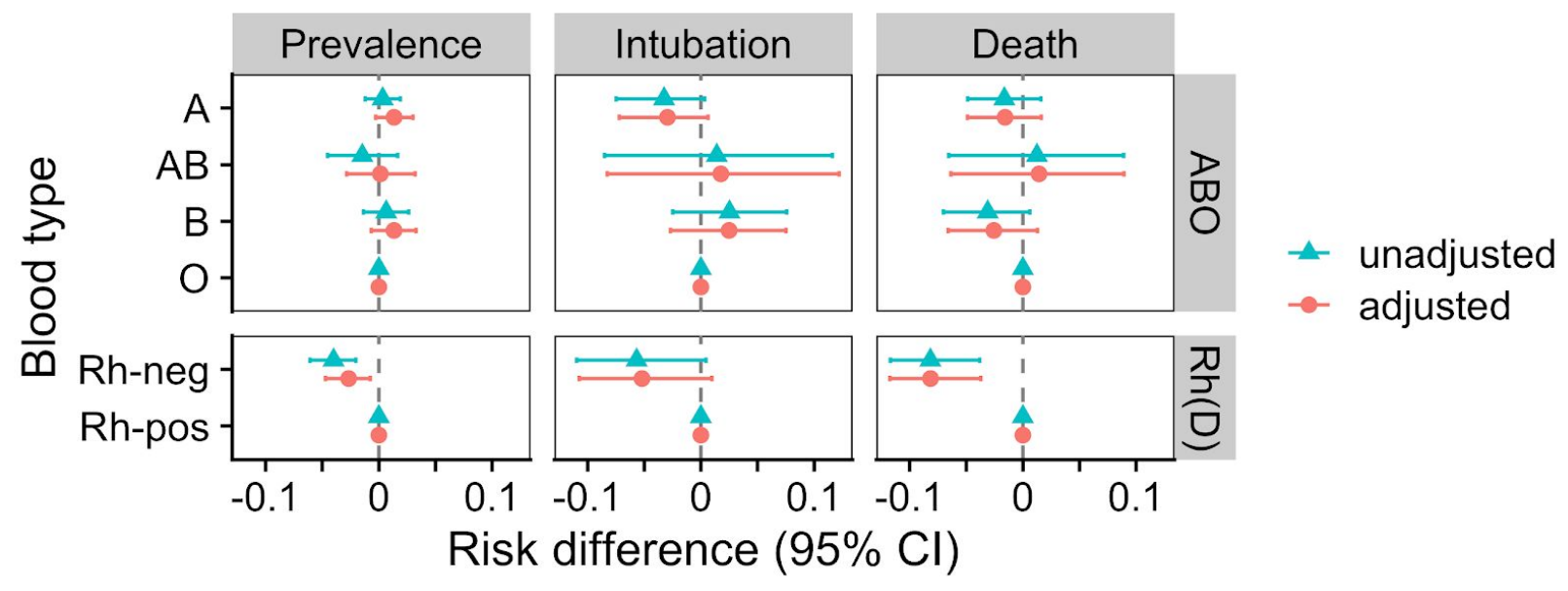




\section{Supplemental information}

Supplementary Figure 1: Flow diagram of inclusion and exclusion criteria for the cohort used. Numbers indicate the number of patients in each group. Groups on the right were excluded.

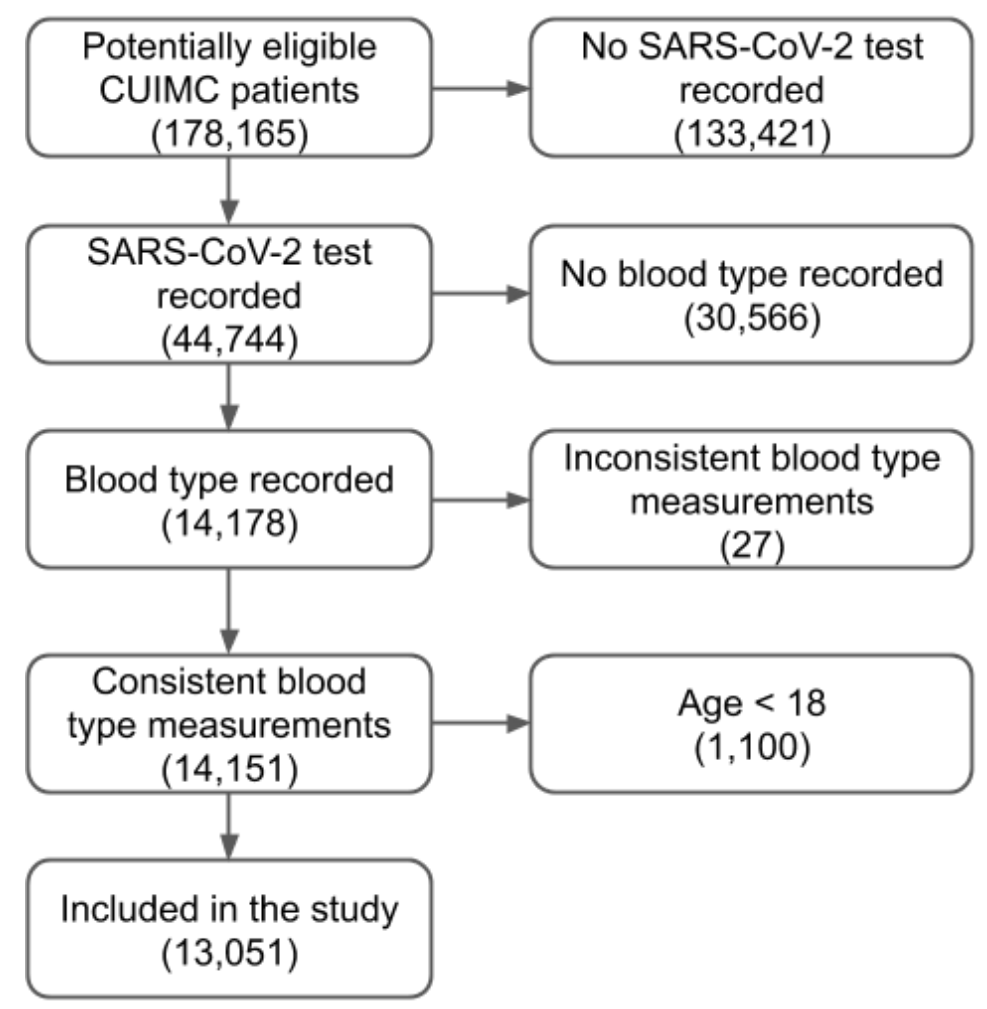

Supplementary Figure 2: Graphical model of the system under investigation. We sought to estimate the total effects of blood type on the COVID-19 outcomes under investigation. Confounding can be controlled by adjusting for ancestry. Selection bias cannot be controlled fully, and as a result, our estimates are conditional on presentation to the hospital during the COVID-19 pandemic.

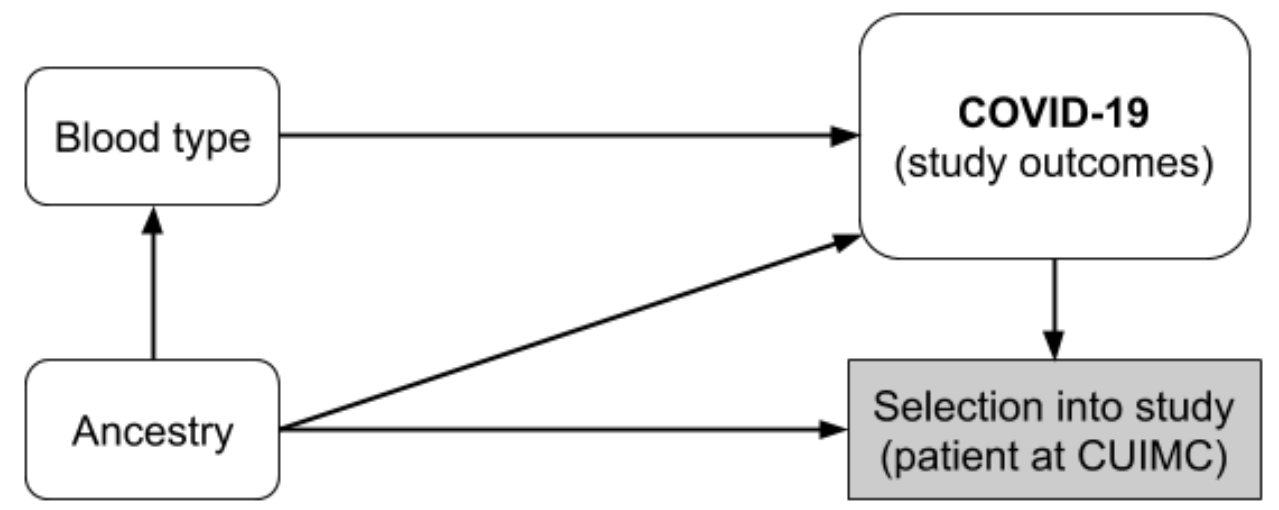


medRxiv preprint doi: https://doi.org/10.1101/2020.04.08.20058073; this version posted September 10, 2020. The copyright holder for this preprint (which was not certified by peer review) is the author/funder, who has granted medRxiv a license to display the preprint in perpetuity.

It is made available under a CC-BY 4.0 International license.

Supplementary Table 1: Chi-squared tests to evaluate whether the dependence between blood

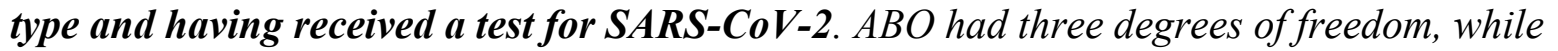
$R h(D)$ had one degree of freedom.

\begin{tabular}{|l|l|l|l|l|}
\hline $\begin{array}{l}\text { Blood } \\
\text { group }\end{array}$ & \multicolumn{1}{|c|}{ SARS-CoV-2 tested } & \multicolumn{1}{|c|}{ non-SARS-CoV-2-tested } & Chi-squared & p-value \\
\hline ABO & A: $4298(32.9 \%)$, AB: $559(4.3 \%)$, B: & $\begin{array}{l}\text { A: } 34156(32.7 \%), \text { AB: } 4405(4.2 \%), \\
\text { B: } 15590(14.9 \%), \text { O: } 50305(48.2 \%)\end{array}$ & 5.79 & 0.122 \\
\hline 2033 (15.6\%), O: 6161 $(47.2 \%)$ & neg: $1195(9.2 \%)$, pos: $11856(90.8 \%)$ & neg: $9644(9.2 \%)$, pos: $94812(90.8 \%)$ & 0.0716 & 0.789 \\
\hline
\end{tabular}

\section{References}

1. Coronavirus disease 2019 (COVID-19) Weekly Epidemiological Update 1 World Health Organization

WHO Coronavirus disease 2019 Weekly Epidemiological Updates (2020-08-17)

https://www.who.int/docs/default-source/coronaviruse/situation-reports/20200817-weekly-epi-up date-1.pdf

2. Clinical course and risk factors for mortality of adult inpatients with COVID-19 in Wuhan, China: a retrospective cohort study

Fei Zhou, Ting Yu, Ronghui Du, Guohui Fan, Ying Liu, Zhibo Liu, Jie Xiang, Yeming Wang, Bin Song, Xiaoying Gu, ... Bin Cao

The Lancet (2020-03) https://doi.org/ggnxb3

DOI: 10.1016/s0140-6736(20)30566-3 · PMID: 32171076 · PMCID: PMC7270627

3. Risk factors of critical \& mortal COVID-19 cases: A systematic literature review and meta-analysis

Zhaohai Zheng, Fang Peng, Buyun Xu, Jingjing Zhao, Huahua Liu, Jiahao Peng, Qingsong Li, Chongfu Jiang, Yan Zhou, Shuqing Liu, ... Weiliang Tang

Journal of Infection (2020-08) https://doi.org/ggv36z

DOI: 10.1016/j.jinf.2020.04.021 · PMID: 32335169 • PMCID: PMC7177098

4. Relationship between the ABO Blood Group and the COVID-19 Susceptibility

Jiao Zhao, Yan Yang, Hanping Huang, Dong Li, Dongfeng Gu, Xiangfeng Lu, Zheng Zhang, Lei Liu, Ting Liu, Yukun Liu, ... Peng George Wang

medRxiv (2020-03-27) https://doi.org/ggpn3d

DOI: $10.1101 / 2020.03 .11 .20031096$

5. Genomewide Association Study of Severe Covid-19 with Respiratory Failure David Ellinghaus, Frauke Degenhardt, Luis Bujanda, Maria Buti, Agustín Albillos, Pietro Invernizzi, Javier Fernández, Daniele Prati, Guido Baselli, Rosanna Asselta, ... Tom H. Karlsen New England Journal of Medicine (2020-06-17) https://doi.org/gg2pqx

DOI: 10.1056/nejmoa2020283 • PMID: 32558485 • PMCID: PMC7315890

6. A genome-wide association study identifies new loci for ACE activity: potential implications for response to $\mathrm{ACE}$ inhibitor C-M Chung, R-Y Wang, J-W Chen, CSJ Fann, H-B Leu, H-Y Ho, C-T Ting, T-H Lin, S-H Sheu, 
medRxiv preprint doi: https://doi.org/10.1101/2020.04.08.20058073; this version posted September 10, 2020. The copyright holder for this preprint (which was not certified by peer review) is the author/funder, who has granted medRxiv a license to display the preprint in perpetuity.

It is made available under a CC-BY 4.0 International license .

W-C Tsai, ... W-H Pan

The Pharmacogenomics Journal (2010-01-12) https://doi.org/ffzgpv

DOI: 10.1038/tpj.2009.70 • PMID: 20066004

7. Genome-wide association study of hematological and biochemical traits in a Japanese population

Yoichiro Kamatani, Koichi Matsuda, Yukinori Okada, Michiaki Kubo, Naoya Hosono, Yataro Daigo, Yusuke Nakamura, Naoyuki Kamatani

Nature Genetics (2010-02-07) https://doi.org/d39wm9

DOI: 10.1038/ng.531 · PMID: 20139978

8. The Allelic Landscape of Human Blood Cell Trait Variation and Links to Common Complex Disease

William J. Astle, Heather Elding, Tao Jiang, Dave Allen, Dace Ruklisa, Alice L. Mann, Daniel Mead, Heleen Bouman, Fernando Riveros-Mckay, Myrto A. Kostadima, ... Nicole Soranzo Cell (2016-11) https://doi.org/f9dvev

DOI: 10.1016/j.cell.2016.10.042 · PMID: 27863252 • PMCID: PMC5300907

9. Genome-wide Trans-ethnic Meta-analysis Identifies Seven Genetic Loci Influencing Erythrocyte Traits and a Role for RBPMS in Erythropoiesis

Frank J. A. van Rooij, Rehan Qayyum, Albert V. Smith, Yi Zhou, Stella Trompet, Toshiko

Tanaka, Margaux F. Keller, Li-Ching Chang, Helena Schmidt, Min-Lee Yang, ... Santhi K. Ganesh

The American Journal of Human Genetics (2017-01) https://doi.org/f9knrj

DOI: 10.1016/j.ajhg.2016.11.016 • PMID: 28017375 • PMCID: PMC5223059

10. Genetic analysis of quantitative traits in the Japanese population links cell types to complex human diseases

Masahiro Kanai, Masato Akiyama, Atsushi Takahashi, Nana Matoba, Yukihide Momozawa, Masashi Ikeda, Nakao Iwata, Shiro Ikegawa, Makoto Hirata, Koichi Matsuda, ... Yoichiro

Kamatani

Nature Genetics (2018-02-05) https://doi.org/gc88bp

DOI: 10.1038/s41588-018-0047-6 • PMID: 29403010

\section{Novel Associations of Multiple Genetic Loci With Plasma Levels of Factor VII, Factor VIII, and von Willebrand Factor}

Nicholas L. Smith, Ming-Huei Chen, Abbas Dehghan, David P. Strachan, Saonli Basu, Nicole

Soranzo, Caroline Hayward, Igor Rudan, Maria Sabater-Lleal, Joshua C. Bis, ... Wellcome Trust Case Control Consortium;

Circulation (2010-03-30) https://doi.org/d37tns

DOI: 10.1161/circulationaha.109.869156 • PMID: 20231535 • PMCID: PMC2861278

\section{Ischemic stroke is associated with the $A B O$ locus: The EuroCLOT study}

Frances M. K. Williams, Angela M. Carter, Pirro G. Hysi, Gabriela Surdulescu, Dylan Hodgkiss, Nicole Soranzo, Matthew Traylor, Steve Bevan, Martin Dichgans, Peter M. W. Rothwell, ... on Behalf of the EuroCLOT Investigators the Wellcome Trust Case Control Consortium 2 MOnica Risk, Genetics, Archiving and Monograph MetaStroke and the International Stroke Genetics 
Consortium

Annals of Neurology (2013-01) https://doi.org/f22kds

DOI: $10.1002 /$ ana.23838 PMID: $23381943 \cdot$ PMCID: PMC3582024

13. Genome-wide association studies identify genetic loci for low von Willebrand factor levels

Janine van Loon, Abbas Dehghan, Tang Weihong, Stella Trompet, Wendy L McArdle, Folkert FW Asselbergs, Ming-Huei Chen, Lorna M Lopez, Jennifer E Huffman, Frank WG Leebeek, ... Christopher O'Donnell

European Journal of Human Genetics (2015-10-21) https://doi.org/gg8q93

DOI: 10.1038/ejhg.2015.222 • PMID: 26486471·PMCID: PMC5070882

14. Genome-Wide Association Transethnic Meta-Analyses Identifies Novel Associations Regulating Coagulation Factor VIII and von Willebrand Factor Plasma Levels Maria Sabater-Lleal, Jennifer E. Huffman, Paul S. de Vries, Jonathan Marten, Michael A. Mastrangelo, Ci Song, Nathan Pankratz, Cavin K. Ward-Caviness, Lisa R. Yanek, Stella Trompet, ... INVENT Consortium; MEGASTROKE Consortium of the International Stroke Genetics Consortium (ISGC)

Circulation (2019-01-29) https://doi.org/gg8q99

DOI: 10.1161/circulationaha.118.034532 · PMID: 30586737 • PMCID: PMC6438386

15. Identification of ADAMTS7 as a novel locus for coronary atherosclerosis and association of $\mathrm{ABO}$ with myocardial infarction in the presence of coronary atherosclerosis: two genome-wide association studies

Muredach P Reilly, Mingyao Li, Jing He, Jane F Ferguson, Ioannis M Stylianou, Nehal N Mehta, Mary Susan Burnett, Joseph M Devaney, Christopher W Knouff, John R Thompson, ... Daniel J Rader

The Lancet (2011-01) https://doi.org/fms4dn

DOI: 10.1016/s0140-6736(10)61996-4 · PMID: 21239051 • PMCID: PMC3297116

16. A comprehensive 1000 Genomes-based genome-wide association meta-analysis of coronary artery disease

the CARDIoGRAMplusC4D Consortium

Nature Genetics (2015-09-07) https://doi.org/f3m2c6

DOI: 10.1038/ng.3396 • PMID: 26343387 - PMCID: PMC4589895

17. Large-scale association analysis identifies 13 new susceptibility loci for coronary artery disease

Heribert Schunkert, Inke R König, Sekar Kathiresan, Muredach P Reilly, Themistocles L

Assimes, Hilma Holm, Michael Preuss, Alexandre FR Stewart, Maja Barbalic, Christian Gieger, ... the CARDIoGRAM Consortium

Nature Genetics (2011-03-06) https://doi.org/d5z4rh

DOI: 10.1038/ng.784 • PMID: 21378990 · PMCID: PMC3119261

18. Shared Genetic Susceptibility to Ischemic Stroke and Coronary Artery Disease Martin Dichgans, Rainer Malik, Inke R. König, Jonathan Rosand, Robert Clarke, Solveig Gretarsdottir, Gudmar Thorleifsson, Braxton D. Mitchell, Themistocles L. Assimes, Christopher 
Levi, ... Collaborators/second tier of authors:

Stroke (2014-01) https://doi.org/f5m2b4

DOI: 10.1161/strokeaha.113.002707 · PMID: 24262325 • PMCID: PMC4112102

19. Association analyses based on false discovery rate implicate new loci for coronary artery disease

Christopher P Nelson, Anuj Goel, Adam S Butterworth, Stavroula Kanoni, Tom R Webb, Eirini Marouli, Lingyao Zeng, Ioanna Ntalla, Florence Y Lai, Jemma C Hopewell, ... Panos Deloukas Nature Genetics (2017-07-17) https://doi.org/gbnnwd

DOI: 10.1038/ng.3913 • PMID: 28714975

20. Identification of 64 Novel Genetic Loci Provides an Expanded View on the Genetic Architecture of Coronary Artery Disease

Pim van der Harst, Niek Verweij

Circulation Research (2018-02-02) https://doi.org/gcw7qj

DOI: 10.1161/circresaha.117.312086 • PMID: 29212778 • PMCID: PMC5805277

21. Multiancestry genome-wide association study of $\mathbf{5 2 0 , 0 0 0}$ subjects identifies 32 loci associated with stroke and stroke subtypes

Rainer Malik, Ganesh Chauhan, Matthew Traylor, Muralidharan Sargurupremraj, Yukinori Okada, Aniket Mishra, Loes Rutten-Jacobs, Anne-Katrin Giese, Sander W. van der Laan, Solveig Gretarsdottir, ... MEGASTROKE Consortium

Nature Genetics (2018-03-12) https://doi.org/gc8wmv

DOI: 10.1038/s41588-018-0058-3 · PMID: 29531354 • PMCID: PMC5968830

22. An Expanded Genome-Wide Association Study of Type 2 Diabetes in Europeans

Robert A. Scott, Laura J. Scott, Reedik Mägi, Letizia Marullo, Kyle J. Gaulton, Marika

Kaakinen, Natalia Pervjakova, Tune H. Pers, Andrew D. Johnson, John D. Eicher, ... Inga

Prokopenko

Diabetes (2017-11) https://doi.org/gbvxgt

DOI: $10.2337 / \mathrm{db} 16-1253 \cdot$ PMID: $28566273 \cdot$ PMCID: PMC5652602

23. Genome-wide association analyses identify 143 risk variants and putative regulatory mechanisms for type 2 diabetes

Angli Xue, Yang Wu, Zhihong Zhu, Futao Zhang, Kathryn E. Kemper, Zhili Zheng, Loic Yengo, Luke R. Lloyd-Jones, Julia Sidorenko, Yeda Wu, ... eQTLGen Consortium

Nature Communications (2018-07-27) https://doi.org/gdvqcz

DOI: 10.1038/s41467-018-04951-W • PMID: 30054458 • PMCID: PMC6063971

24. Fine-mapping type 2 diabetes loci to single-variant resolution using high-density imputation and islet-specific epigenome maps

Anubha Mahajan, Daniel Taliun, Matthias Thurner, Neil R. Robertson, Jason M. Torres, N.

William Rayner, Anthony J. Payne, Valgerdur Steinthorsdottir, Robert A. Scott, Niels Grarup, ...

Mark I. McCarthy

Nature Genetics (2018-10-08) https://doi.org/gfb68d

DOI: 10.1038/s41588-018-0241-6 • PMID: $30297969 \cdot$ PMCID: PMC6287706 
25. Common susceptibility alleles are unlikely to contribute as strongly as the FV and ABO loci to VTE risk: results from a GWAS approach

David-Alexandre Trégouët, Simon Heath, Noémie Saut, Christine Biron-Andreani, Jean-François Schved, Gilles Pernod, Pilar Galan, Ludovic Drouet, Diana Zelenika, Irène Juhan-Vague, ... Pierre-Emmanuel Morange

Blood (2009-05-21) https://doi.org/fsvjbh

DOI: 10.1182/blood-2008-11-190389 · PMID: 19278955

26. Genetics of Venous Thrombosis: Insights from a New Genome Wide Association Study Marine Germain, Noémie Saut, Nicolas Greliche, Christian Dina, Jean-Charles Lambert, Claire Perret, William Cohen, Tiphaine Oudot-Mellakh, Guillemette Antoni, Marie-Christine Alessi, ... Pierre-Emmanuel Morange PLoS ONE (2011-09-27) https://doi.org/btdd2f

DOI: 10.1371/journal.pone.0025581 • PMID: 21980494 · PMCID: PMC3181335

27. A genome-wide association study of venous thromboembolism identifies risk variants in chromosomes 1q24.2 and 9q

J. A. HEIT, S. M. ARMASU, Y. W. ASMANN, J. M. CUNNINGHAM, M. E. MATSUMOTO, T. M. PETTERSON, M. DE ANDRADE

Journal of Thrombosis and Haemostasis (2012-08) https://doi.org/f366q9

DOI: 10.1111/j.1538-7836.2012.04810.x · PMID: 22672568 · PMCID: PMC3419811

\section{A Genome-Wide Association Study for Venous Thromboembolism: The Extended}

Cohorts for Heart and Aging Research in Genomic Epidemiology (CHARGE) Consortium Weihong Tang, Martina Teichert, Daniel I. Chasman, John A. Heit, Pierre-Emmanuel Morange, Guo Li, Nathan Pankratz, Frank W. Leebeek, Guillaume Paré, Mariza de Andrade, ... Nicholas L. Smith

Genetic Epidemiology (2013-07) https://doi.org/f42gwd

DOI: 10.1002/gepi.21731 · PMID: 23650146 · PMCID: PMC3990406

29. Meta-analysis of 65,734 Individuals Identifies TSPAN15 and SLC44A2 as Two Susceptibility Loci for Venous Thromboembolism

Marine Germain, Daniel I. Chasman, Hugoline de Haan, Weihong Tang, Sara Lindström, Lu-Chen Weng, Mariza de Andrade, Marieke C.H. de Visser, Kerri L. Wiggins, Pierre Suchon, ... Pierre-Emmanuel Morange

The American Journal of Human Genetics (2015-04) https://doi.org/f3phn3

DOI: 10.1016/j.ajhg.2015.01.019 • PMID: 25772935 • PMCID: PMC4385184

30. Genetic Analysis of Venous Thromboembolism in UK Biobank Identifies the ZFPM2 Locus and Implicates Obesity as a Causal Risk Factor Derek Klarin, Connor A. Emdin, Pradeep Natarajan, Mark F. Conrad, Sekar Kathiresan Circulation: Cardiovascular Genetics (2017-04) https://doi.org/gg8q98

DOI: 10.1161/circgenetics.116.001643 · PMID: 28373160 · PMCID: PMC5395047

31. Genomic and transcriptomic association studies identify 16 novel susceptibility loci for venous thromboembolism

Sara Lindström, Lu Wang, Erin N. Smith, William Gordon, Astrid van Hylckama Vlieg, Mariza 
medRxiv preprint doi: https://doi.org/10.1101/2020.04.08.20058073; this version posted September 10, 2020. The copyright holder for this preprint (which was not certified by peer review) is the author/funder, who has granted medRxiv a license to display the preprint in perpetuity.

It is made available under a CC-BY 4.0 International license .

de Andrade, Jennifer A. Brody, Jack W. Pattee, Jeffrey Haessler, Ben M. Brumpton, ... The CHARGE Hemostasis Working Group Blood (2019-11-07) https://doi.org/ggmxcr

DOI: 10.1182/blood.2019000435 · PMID: 31420334 · PMCID: PMC6871304

32. Genome-wide association analysis of venous thromboembolism identifies new risk loci and genetic overlap with arterial vascular disease

Derek Klarin, Emma Busenkell, Renae Judy, Julie Lynch, Michael Levin, Jeffery Haessler, Krishna Aragam, Mark Chaffin, Mary Haas, Sara Lindström, ... Veterans Affairs' Million Veteran Program

Nature Genetics (2019-11-01) https://doi.org/ggen7d

DOI: 10.1038/s41588-019-0519-3 · PMID: 31676865 · PMCID: PMC6858581

33. Non-O Blood Type Is the Commonest Genetic Risk Factor for VTE: Results from a Meta-Analysis of the Literature

Francesco Dentali, Anna Sironi, Walter Ageno, Sara Turato, Carlo Bonfanti, Francesco Frattini, Silvia Crestani, Massimo Franchini

Seminars in Thrombosis and Hemostasis (2012-06-27) https://doi.org/f33vdg

DOI: 10.1055/s-0032-1315758 · PMID: 22740183

34. Anticoagulant treatment is associated with decreased mortality in severe coronavirus disease 2019 patients with coagulopathy

Ning Tang, Huan Bai, Xing Chen, Jiale Gong, Dengju Li, Ziyong Sun

Journal of Thrombosis and Haemostasis (2020-04-27) https://doi.org/ggqsrv

DOI: $10.1111 /$ jth.14817 P PMID: 32220112

35. High incidence of venous thromboembolic events in anticoagulated severe COVID-19 patients

Jean-François Llitjos, Maxime Leclerc, Camille Chochois, Jean-Michel Monsallier, Michel

Ramakers, Malika Auvray, Karim Merouani

Journal of Thrombosis and Haemostasis (2020-05-27) https://doi.org/ggtsjp

DOI: 10.1111/jth.14869 · PMID: $32320517 \cdot$ PMCID: PMC7264774

36. Incidence of venous thromboembolism in hospitalized patients with COVID-19

Saskia Middeldorp, Michiel Coppens, Thijs F. Haaps, Merijn Foppen, Alexander P. Vlaar, Marcella C. A. Müller, Catherine C. S. Bouman, Ludo F. M. Beenen, Ruud S. Kootte, Jarom Heijmans, ... Nick Es

Journal of Thrombosis and Haemostasis (2020-07-27) https://doi.org/ggv2vb

DOI: $10.1111 /$ jth.14888 PMID: 32369666

37. Venous and arterial thromboembolic complications in COVID-19 patients admitted to an academic hospital in Milan, Italy

Corrado Lodigiani, Giacomo Iapichino, Luca Carenzo, Maurizio Cecconi, Paola Ferrazzi, Tim

Sebastian, Nils Kucher, Jan-Dirk Studt, Clara Sacco, Bertuzzi Alexia, ... Stefano Barco

Thrombosis Research (2020-07) https://doi.org/ggvcft

DOI: 10.1016/j.thromres.2020.04.024 • PMID: 32353746 • PMCID: PMC7177070 
38. Coagulation abnormalities and thrombosis in patients with COVID-19 Marcel Levi, Jecko Thachil, Toshiaki Iba, Jerrold H Levy

The Lancet Haematology (2020-06) https://doi.org/ggx259

DOI: 10.1016/s2352-3026(20)30145-9 • PMID: 32407672 · PMCID: PMC7213964

39. COVID-19-Related Severe Hypercoagulability in Patients Admitted to Intensive Care Unit for Acute Respiratory Failure

Luca Spiezia, Annalisa Boscolo, Francesco Poletto, Lorenzo Cerruti, Ivo Tiberio, Elena

Campello, Paolo Navalesi, Paolo Simioni

Thrombosis and Haemostasis (2020-04-21) https://doi.org/ggx3vp

DOI: 10.1055/s-0040-1710018 • PMID: 32316063 • PMCID: PMC7295272

40. Autopsy Findings and Venous Thromboembolism in Patients With COVID-19

Dominic Wichmann, Jan-Peter Sperhake, Marc Lütgehetmann, Stefan Steurer, Carolin Edler, Axel Heinemann, Fabian Heinrich, Herbert Mushumba, Inga Kniep, Ann Sophie Schröder, ... Stefan Kluge

Annals of Internal Medicine (2020-08-18) https://doi.org/ggv2pm

DOI: 10.7326/m20-2003 • PMID: 32374815 • PMCID: PMC7240772

41. The need to manage the risk of thromboembolism in COVID-19 patients

Inayat Hussain Khan, Sugeevan Savarimuthu, Marco Shiu Tsun Leung, Amer Harky

Journal of Vascular Surgery (2020-09) https://doi.org/ggwqwz

DOI: 10.1016/j.jvs.2020.05.015 • PMID: 32417304 • PMCID: PMC7224653

\section{ABO Blood Group and Susceptibility to Severe Acute Respiratory Syndrome} JAMA

(2005-03-23) https://doi.org/ftkw6v

DOI: 10.1001/jama.293.12.1450-c · PMID: 15784866

43. ABO Blood Group Phenotypes and Plasmodium falciparum Malaria: Unlocking a Pivotal Mechanism

María-Paz Loscertales, Stephen Owens, James O’Donnell, James Bunn, Xavier

Bosch-Capblanch, Bernard J. Brabin

Advances in Parasitology (2007) https://doi.org/db42m2

DOI: $10.1016 / \mathrm{s} 0065-308 x(07) 65001-5$

44. Attachment of Helicobacter pylori to human gastric epithelium mediated by blood group antigens

T Boren, P Falk, K. Roth, G Larson, S Normark

Science (1993-12-17) https://doi.org/d3wbh6

DOI: $10.1126 /$ science.8018146 PMID: 8018146

45. Human susceptibility and resistance to Norwalk virus infection

Lisa Lindesmith, Christine Moe, Severine Marionneau, Nathalie Ruvoen, Xi Jiang, Lauren Lindblad, Paul Stewart, Jacques LePendu, Ralph Baric 
Nature Medicine (2003-04-14) https://doi.org/c7xvwh

DOI: $10.1038 / \mathrm{nm} 860 \cdot$ PMID: 12692541

46. ABO blood group, hepatitis B viral infection and risk of pancreatic cancer

De-Shen Wang, Dong-Liang Chen, Chao Ren, Zhi-Qiang Wang, Miao-Zhen Qiu, Hui-Yan Luo, Dong-Sheng Zhang, Feng-Hua Wang, Yu-Hong Li, Rui-Hua Xu

International Journal of Cancer (2012-07-15) https://doi.org/cpfxbm

DOI: 10.1002/ijc.26376 · PMID: 21858814

\section{Relation of Infection with Neisseria gonorrhoeae to ABO Blood Groups}

M. T. Foster, A. H. Labrum

Journal of Infectious Diseases (1976-02-01) https://doi.org/dt9x9d

DOI: 10.1093/infdis/133.3.329 • PMID: 1254989

48. The relationship between blood groups and disease

David. J. Anstee

Blood (2010-06-10) https://doi.org/cks8q2

DOI: 10.1182/blood-2010-01-261859·PMID: 20308598

49. Serological weak D phenotypes: a review and guidance for interpreting the $\mathbf{R h D}$ blood type using the $R H D$ genotype

S. Gerald Sandler, Leonard N. Chen, Willy A. Flegel

British Journal of Haematology (2017-10) https://doi.org/f964n6

DOI: 10.1111/bjh.14757 · PMID: 28508413 · PMCID: PMC5612847

50. Influence of latent Toxoplasma infection on human personality, physiology and morphology: pros and cons of the Toxoplasma-human model in studying the manipulation hypothesis

J. Flegr

Journal of Experimental Biology (2012-12-05) https://doi.org/f4hh67

DOI: $10.1242 /$ jeb.073635 · PMID: 23225875

51. Population Structure and Epidemiology of Toxoplasma gondii

M. L. Dardé, D. Ajzenberg, J. Smith

Elsevier (2007) https://doi.org/fs2wxp

DOI: 10.1016/b978-012369542-0/50005-2

52. COVID-19: Data Main - NYC Health

https://www1.nyc.gov/site/doh/covid/covid-19-data.page

53. ABO and $R h(D)$ phenotype frequencies of different racial/ ethnic groups in the United States

George Garratty, Simone A. Glynn, Robin McEntire, Retrovirus Epidemiology Donor Study

Transfusion (2004-05) https://doi.org/dkshr5

DOI: 10.1111/j.1537-2995.2004.03338.x · PMID: 15104651 
medRxiv preprint doi: https://doi.org/10.1101/2020.04.08.20058073; this version posted September 10, 2020. The copyright holder for this preprint (which was not certified by peer review) is the author/funder, who has granted medRxiv a license to display the preprint in perpetuity.

It is made available under a CC-BY 4.0 International license .

54. Absolute risk reductions and numbers needed to treat can be obtained from adjusted survival models for time-to-event outcomes

Peter C. Austin

Journal of Clinical Epidemiology (2010-01) https://doi.org/dgj9pv

DOI: 10.1016/j.jclinepi.2009.03.012 • PMID: 19595575

55. False-negative of RT-PCR and prolonged nucleic acid conversion in COVID-19: Rather than recurrence

Ai Tang Xiao, Yi Xin Tong, Sheng Zhang

Journal of Medical Virology (2020-04-09) https://doi.org/ggx3gt

DOI: 10.1002/jmv.25855 • PMID: 32270882 - PMCID: PMC7262304

56. COVID-19 Testing

Colin P. West, Victor M. Montori, Priya Sampathkumar

Mayo Clinic Proceedings (2020-06) https://doi.org/ggr6q6

DOI: 10.1016/j.mayocp.2020.04.004 • PMID: 32376102 • PMCID: PMC7151274

57. Negative Nasopharyngeal and Oropharyngeal Swab Does Not Rule Out COVID-19

Poramed Winichakoon, Romanee Chaiwarith, Chalerm Liwsrisakun, Parichat Salee, Aree

Goonna, Atikun Limsukon, Quanhathai Kaewpoowat

Journal of Clinical Microbiology (2020-02-26) https://doi.org/ggpw9m

DOI: 10.1128/jcm.00297-20 • PMID: 32102856 • PMCID: PMC7180262

58. A Proportional Hazards Model for the Subdistribution of a Competing Risk

Jason P. Fine, Robert J. Gray

Journal of the American Statistical Association (1999-06) https://doi.org/gdtmsf

DOI: 10.1080/01621459.1999.10474144

59. Coronavirus Disease 2019 (COVID-19)

$\mathrm{CDC}$

Centers for Disease Control and Prevention (2020-02-11)

https://www.cdc.gov/coronavirus/2019-ncov/hcp/return-to-work.html

60. Coronavirus Disease 2019 (COVID-19)

$\mathrm{CDC}$

Centers for Disease Control and Prevention (2020-02-11)

https://www.cdc.gov/coronavirus/2019-ncov/hcp/duration-isolation.html

61. Estimation of the asymptomatic ratio of novel coronavirus infections (COVID-19)

Hiroshi Nishiura, Tetsuro Kobayashi, Ayako Suzuki, Sung-Mok Jung, Katsuma Hayashi, Ryo

Kinoshita, Yichi Yang, Baoyin Yuan, Andrei R. Akhmetzhanov, Natalie M. Linton, Takeshi

Miyama

International Journal of Infectious Diseases (2020-03) https://doi.org/ggp6hp

DOI: 10.1016/j.ijid.2020.03.020 • PMID: 32179137 • PMCID: PMC7270890

62. Temporal dynamics in viral shedding and transmissibility of COVID-19

Xi He, Eric H. Y. Lau, Peng Wu, Xilong Deng, Jian Wang, Xinxin Hao, Yiu Chung Lau, Jessica 
Y. Wong, Yujuan Guan, Xinghua Tan, ... Gabriel M. Leung

Nature Medicine (2020-04-15) https://doi.org/ggr99q

DOI: 10.1038/s41591-020-0869-5 - PMID: 32296168

63. Comparison of Clinical Characteristics of Patients with Asymptomatic vs Symptomatic Coronavirus Disease 2019 in Wuhan, China

Rongrong Yang, Xien Gui, Yong Xiong

JAMA Network Open (2020-05-27) https://doi.org/ggx2nn

DOI: 10.1001/jamanetworkopen.2020.10182 · PMID: 32459353 • PMCID: PMC7254178

64. Clinical characteristics of asymptomatic and symptomatic patients with mild COVID-19

G.-u. Kim, M.-J. Kim, S. H. Ra, J. Lee, S. Bae, J. Jung, S.-H. Kim

Clinical Microbiology and Infection (2020-07) https://doi.org/ggv3bh

DOI: 10.1016/j.cmi.2020.04.040 • PMID: 32360780 • PMCID: PMC7252018

65. Variation in False-Negative Rate of Reverse Transcriptase Polymerase Chain

Reaction-Based SARS-CoV-2 Tests by Time Since Exposure

Lauren M. Kucirka, Stephen A. Lauer, Oliver Laeyendecker, Denali Boon, Justin Lessler

Annals of Internal Medicine (2020-08-18) https://doi.org/ggwq83

DOI: $10.7326 / \mathrm{m} 20-1495 \cdot$ PMID: $32422057 \cdot$ PMCID: PMC7240870

66. Sequence variation at the human ABO locus

S. P. YIP

Annals of Human Genetics (2002-01) https://doi.org/bpsx99

DOI: 10.1017/s0003480001008995 · PMID: 12014997

67. A Class of \$K\$-Sample Tests for Comparing the Cumulative Incidence of a Competing Risk

Robert J. Gray

The Annals of Statistics (1988-09) https://doi.org/dhv2kf

DOI: 10.1214/aos/1176350951

68. Open collaborative writing with Manubot

Daniel S. Himmelstein, Vincent Rubinetti, David R. Slochower, Dongbo Hu, Venkat S. Malladi, Casey S. Greene, Anthony Gitter

PLOS Computational Biology (2019-06-24) https://doi.org/c7np

DOI: 10.1371/journal.pcbi.1007128 · PMID: 31233491 • PMCID: PMC6611653 